ORIGINAL ARTICLE

\section{A Self-Regulation Program for Maintenance of Weight Loss}

\author{
Rena R. Wing, Ph.D., Deborah F. Tate, Ph.D., Amy A. Gorin, Ph.D., \\ Hollie A. Raynor, Ph.D., and Joseph L. Fava, Ph.D.
}

\section{BACKGROUND}

Since many successful dieters regain the weight they lose, programs that teach maintenance skills are needed. We developed a maintenance program based on self-regulation theory and tested the efficacy of delivering the program face to face or over the Internet.

\section{METHODS}

We randomly assigned 314 participants who had lost a mean of $19.3 \mathrm{~kg}$ of body weight in the previous 2 years to one of three groups: a control group, which received quarterly newsletters (105 participants), a group that received face-to-face intervention (105), and a group that received Internet-based intervention (104). The content of the programs in the two intervention groups was the same, emphasizing daily self-weighing and self-regulation, as was the frequency of contact with the groups. The primary outcome was weight gain over a period of 18 months.

\section{RESULTS}

The mean $( \pm S D)$ weight gain was $2.5 \pm 6.7 \mathrm{~kg}$ in the face-to-face group, $4.7 \pm 8.6 \mathrm{~kg}$ in the Internet group, and $4.9 \pm 6.5 \mathrm{~kg}$ in the control group, with a significant difference between the face-to-face group and the control group ( $2.4 \mathrm{~kg}$; $95 \%$ confidence interval $[\mathrm{CI}], 0.002$ to $10.8 ; \mathrm{P}=0.05)$. The proportion of participants who regained $2.3 \mathrm{~kg}$ or more over the 18 -month period was significantly higher in the control group (72.4\%) than in the face-to-face group (45.7\%; absolute difference, 27\%; 95\% CI, 14 to 39; $\mathrm{P}<0.001$ ) or the Internet group (54.8\%; absolute difference, $18 \%$; $95 \% \mathrm{CI}, 5$ to $30 ; \mathrm{P}=0.008$ ). Daily self-weighing increased in both intervention groups and was associated with a decreased risk of regaining $2.3 \mathrm{~kg}$ or more $(\mathrm{P}<0.001)$.

\section{CONCLUSIONS}

As compared with receiving quarterly newsletters, a self-regulation program based on daily weighing improved maintenance of weight loss, particularly when delivered face to face. (ClinicalTrials.gov number, NCT00067145.)
From Brown Medical School (R.R.W., A.A.G., H.A.R.) and Miriam Hospital (R.R.W., A.A.G., H.A.R., J.L.F.) - both in Providence, RI; and the University of North Carolina, Chapel Hill (D.F.T.). Address reprint requests to $\mathrm{Dr}$. Wing at the Weight Control and Diabetes Research Center, 196 Richmond St., Providence, RI 02903, or at rwing@lifespan.org.

N Engl J Med 2006;355:1563-71. Copyright @ 2006 Massachusetts Medical Society. 
T HE MAJOR CHALLENGE IN THE TREATment of obesity is maintenance of weight loss. Weight-loss programs involving diet, exercise, and behavior modification produce initial weight losses of approximately $10 \%,{ }^{1}$ resulting in clinically important health benefits. ${ }^{2}$ However, most dieters regain about one third of the weight lost during the next year and are typically back to baseline in 3 to 5 years. ${ }^{3}$ Maintenance sessions are included in most programs, since continued contact has been found to be helpful in improving maintenance of weight loss. ${ }^{4}$ Such maintenance sessions have had limited efficacy, perhaps owing to the heterogeneity of weight loss at the start of the maintenance phase and the fact that the sessions are basically extensions of the weight-loss program.

There is a need for maintenance programs that specifically target people who have lost substantial amounts of weight, regardless of how they lost it, and that teach skills specific to the maintenance of weight loss. We report here the results of the Study to Prevent Regain (STOP Regain), a randomized clinical trial testing the efficacy of a face-toface program and an Internet-based program, as compared with a newsletter control group, in preventing weight regain over a period of 18 months. The study focused exclusively on maintenance of weight loss and recruited participants after they had lost a minimum of $10 \%$ of their body weight. The maintenance interventions developed for this trial were based on self-regulation theory ${ }^{5}$ and emphasized comparing current weight with a goal weight (weight at the start of the maintenance phase). Then, depending on the correspondence between these two weights, the participants were taught to adjust their eating and exercise behavior or to provide self-reinforcement. ${ }^{6}$ We hypothesized that the interventions, delivered face to face or over the Internet, would decrease average weight regain and reduce the proportion of participants who regained $2.3 \mathrm{~kg}$ or more during a period of 18 months.

\section{METHODS}

\section{PARTICIPANTS}

We recruited 314 participants between February 2001 and September 2003 through newspaper advertisements, brochures, and contacts with commercial and research weight-control programs in the Rhode Island area (Fig. 1). To be eligible, participants were required to have lost at least
$10 \%$ of their body weight during the prior 2 years. The $10 \%$ weight-loss criterion was selected because of its relevance to clinical measures of health and the 2-year criterion because the risk of regaining weight is greatest during the first several years after weight loss. ${ }^{7,8}$ All participants were required to have a physician, friend, or weightloss counselor complete and sign a form indicating the amount and timing of their weight loss. Exclusion criteria included serious physical disorders (e.g., heart attack or stroke), serious psychological disorders (e.g., bipolar disease, schizophrenia, or an eating disorder), pregnancy, or a planned move. Participants with medical conditions that might affect their ability to safely complete the intervention or their ability to exercise were required to obtain written permission from a physician before entering the study.

\section{STUDY DESIGN}

Participants were stratified according to the amount of prior weight loss (10 to $20 \%$ of body weight vs. more than $20 \%$ of body weight) and then randomly assigned to a control group (105 participants), a face-to-face intervention group (105), or an Internet intervention group (104). The faceto-face format was tested because this approach is used in most weight-control programs and provides a high level of accountability through objective weigh-ins and intensive therapist and peer support. We tested an Internet program because this approach has been shown to be helpful in weight loss and maintenance ${ }^{9-11}$; we reasoned that the Internet program would be more convenient for participants and would therefore produce better attendance at intervention sessions than the faceto-face program. Participants were assessed at 6,12 , and 18 months and were paid $\$ 25$ for attending the 6- and 12-month assessments and \$50 for attending the 18-month assessment. The protocol was approved by the institutional review board at the Miriam Hospital, Providence; written informed consent was obtained from all participants. The authors designed the study and secured funding; they took sole responsibility for treating participants, collecting and analyzing the data, and writing the manuscript; they vouch for the accuracy and completeness of the reported data.

\section{INTERVENTIONS}

The face-to-face and Internet interventions were identical in frequency of contact and content and were intended to teach participants to regulate 


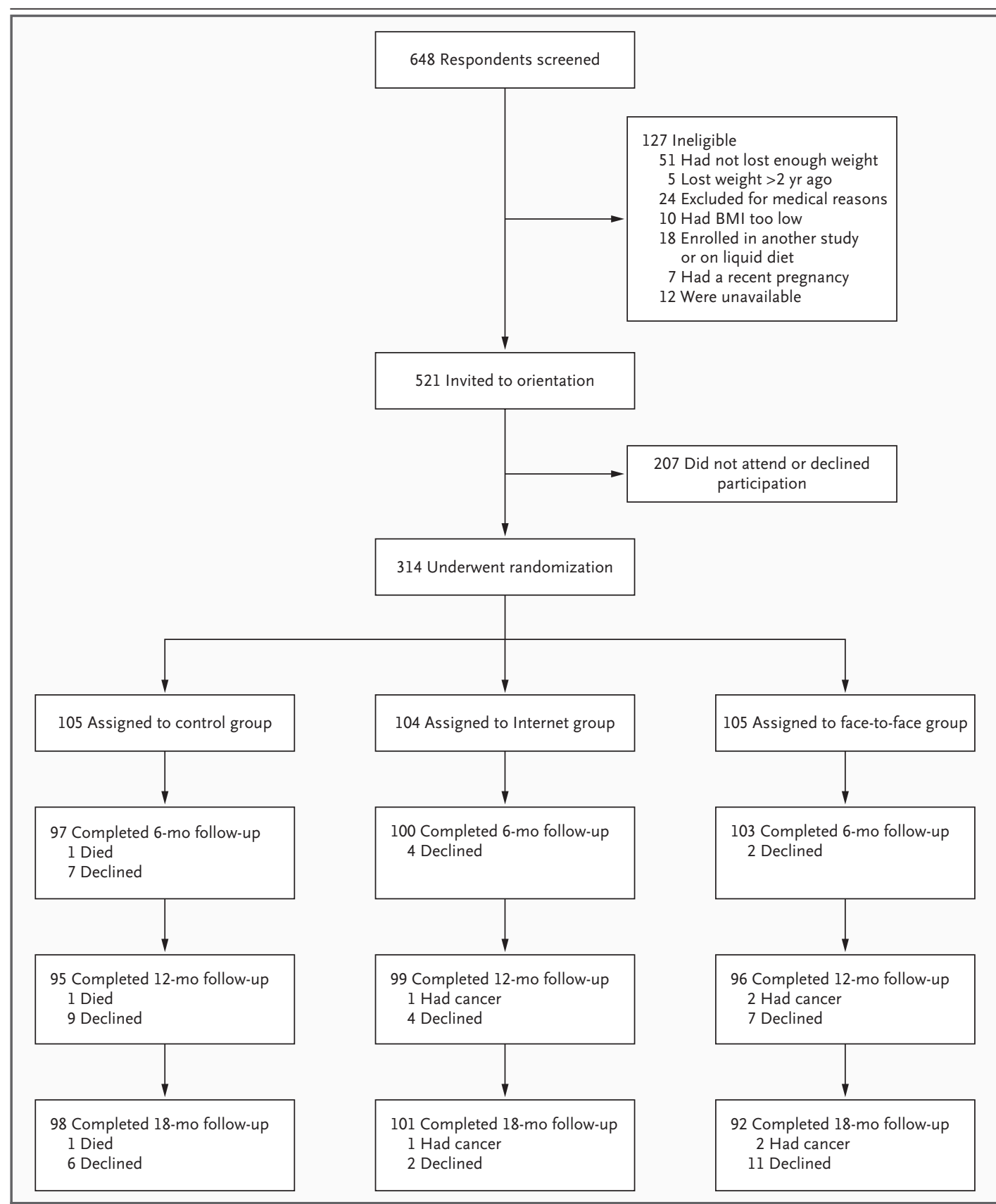

Figure 1. Study Enrollment and Retention.

their body weight. Participants in the intervention groups were given a scale and introduced to a weight-monitoring system based on color zones. They were taught to use the scale in the way they would use a thermostat or home glucose monitor - namely, to determine whether adjustments in energy-balance behaviors were needed.

Since a major difference between weight loss and weight maintenance is the reinforcement a person receives from others, ${ }^{3}$ participants were asked to submit their weight weekly through an automated telephone system (face-to-face group) or a Web-based form (Internet group). Those who reported maintaining their weight, defined as a weight gain of less than $1.4 \mathrm{~kg}^{12}$ over their starting weight, were in the green zone and were pro- 
vided immediate reinforcement with positive automated messages and also received small green gifts monthly (e.g., green gum, green tea, or a green dollar bill) to foster the development of self-reinforcement skills. Participants with weight gains of 1.4 to $2.2 \mathrm{~kg}$ were in the yellow zone and were instructed to use problem-solving skills to bring their weight back to the green zone. Participants with a weight gain of $2.3 \mathrm{~kg}$ or more were in the red zone and were encouraged to restart active weight-loss efforts, using either their initial approach to weight loss or a standard behavioral approach involving a low-calorie, low-fat diet and increased physical activity. Participants in the red zone were also encouraged to use a tool kit provided at the start of the program that included their own weight-loss success story, self-monitoring diaries, a book providing information on calories and fat, a pedometer, and several cans of a meal-replacement product (Slim-Fast, Unilever). Red-zone participants were also offered individual counseling by e-mail (Internet group) or by telephone or in person (face-to-face group) until they returned to their starting weight. Throughout the program, participants in both intervention groups were encouraged to practice eating and exercise behaviors (such as exercising $60 \mathrm{~min}$ utes a day) that have been reported to help maintain weight loss. ${ }^{13,14}$

Both groups attended weekly meetings for the first month and thereafter (for the balance of the 18-month period) attended monthly meetings. In the face-to-face group, meetings were held at a clinic affiliated with Miriam Hospital and included an individual weigh-in and group session. Internet participants were provided with a laptop computer and an Internet connection (if needed) as well as technical support. They attended an introductory session designed to teach them how to use the laptop. Participants in the Internet group had access to a STOP Regain message board and a Web site where treatment lessons and weekly tips were posted and where they reported their weekly weight and physical-activity data. Their group meetings were conducted in a chat room. The same study personnel (nutritionists, exercise physiologists, and clinical psychologists with master's or Ph.D. degrees) led the meetings for both groups; all had experience leading behavioral weight-control groups and received uniform training and supervision for this study.
The control group received a quarterly newsletter with information about diet, exercise, and weight control. These participants had no interaction with intervention staff and were seen at the clinic only for assessments.

\section{END POINTS}

The primary end point was weight gain at 18 months; secondary end points, identified a priori, were the percentage of participants who regained $2.3 \mathrm{~kg}$ or more (chosen because it is larger than the change expected with normal daily weight fluctuation and because of its public health implication) ${ }^{15}$ and changes in diet, activity, and use of behavioral strategies. At each assessment, participants were weighed with a calibrated scale while they were wearing light street clothes, and they completed the Paffenbarger Physical Activity Questionnaire $^{16}$ and the Block Food Frequency Questionnaire. ${ }^{17}$ They also reported their frequency of self-weighing and rated the importance of key behavioral strategies on a scale of 1 to 6 (in which a score of 1 indicates not at all important and a score of 6 of major importance). Height was assessed at baseline with a wall-mounted stadiometer.

\section{STATISTICAL ANALYSIS}

The sample size was selected to provide the study with a statistical power of $80 \%$ to detect a 3-kg difference in weight regain between groups, with the use of a two-tailed test and adjustment for three comparisons. Baseline characteristics were compared with the use of the chi-square test or analysis of variance. Absolute weight gain and the percentage of weight lost from the highest weight reported in the previous 2 years were determined with analysis of variance and repeatedmeasures analysis of covariance, respectively, with dropouts assumed to have regained $0.3 \mathrm{~kg}$ per month, an assumption used in prior studies ${ }^{18,19}$ and similar to the amount regained by controlgroup participants in this trial. Chi-square tests were used to compare groups with respect to the percentage regaining $2.3 \mathrm{~kg}$ or more, with dropouts assumed to have regained this amount. The three pairwise comparisons were tested and Bonferroni's adjustment was used. All analyses were performed with the use of SPSS software, version 13.0, and no interim analyses were conducted. All reported P values are two-sided and reflect Bonferroni's adjustment. 


\section{RESULTS}

Baseline characteristics of the 314 participants who underwent randomization are shown in $\mathrm{Ta}-$ ble 1 . There were no significant differences among the three study groups in any of these measures. The most commonly reported approaches used to lose weight were commercial weight-loss groups (39.5\%), an individual approach with no outside help (22.9\%), and exercise (36.6\%), with an additional approach usually accompanying exercise. The 6- and 12-month assessments were completed by 300 and 290 participants ( $95.5 \%$ and $92.4 \%$ ), respectively, with no significant differences among the groups. The 18-month assessments were completed by 291 participants $(92.7 \%)$, with significantly better attendance in the Internet group than in the face-to-face group $(97.1 \%$ vs. $87.6 \%$, $\mathrm{P}=0.03$ ), but with attendance in neither intervention group significantly different from that of the control group ( $93.3 \%$; $\mathrm{P}=0.20$ and $\mathrm{P}=0.16$, respectively).

\section{ABSOLUTE WEIGHT CHANGE}

The mean $( \pm S D)$ absolute weight gain over the 18 -month period was $2.5 \pm 6.7 \mathrm{~kg}$ in the face-toface group as compared with $4.7 \pm 8.6 \mathrm{~kg}$ in the Internet group and $4.9 \pm 6.5 \mathrm{~kg}$ in the control group (Table 2). There was a significant difference in weight gain between the face-to-face and control groups (absolute difference, $2.4 \mathrm{~kg}$; 95\% confidence interval [CI], 0.002 to $10.8 ; \mathrm{P}=0.05$ ), but not between the face-to-face group and the Internet group (2.2 kg; $95 \% \mathrm{CI},-0.50$ to $10.3 ; \mathrm{P}=0.09$ ), or between the Internet group and the control group (absolute difference, $0.2 \mathrm{~kg}$; 95\% CI, -4.9 to 5.9 ; $\mathrm{P}=1.00$ ). Repeated-measures analysis of covariance, with adjustment for baseline percent weight reduction, showed that the face-to-face group also differed significantly from both the Internet group and the control group with respect to the percentages of weight lost during the 18 months of the trial ( $\mathrm{P}=0.02$ and $\mathrm{P}=0.006$, respectively) (Fig. 2). The failure to find a significant difference between the Internet and control groups on these measures resulted, in part, from the somewhat larger amount of weight regained in the Internet group. Among participants in the red zone, those in the Internet group had regained a mean of $9.8 \pm 8.4 \mathrm{~kg}$ at the end of 18 months, as compared with $7.5 \pm 5.6 \mathrm{~kg}$ in the control group $(\mathrm{P}=0.18)$ and $7.4 \pm 6.4$ in the face-to-face group ( $\mathrm{P}=0.24)$.

\section{PERCENTAGE OF PARTICIPANTS REGAINING 2.3 KG} OR MORE

Assuming that all dropouts regained $2.3 \mathrm{~kg}$ or more, we found that $72.4 \%$ of participants in the control group regained $2.3 \mathrm{~kg}$ or more during the 18 -month period, as compared with $54.8 \%$ of participants in the Internet group (absolute difference,

\begin{tabular}{|c|c|c|c|}
\hline Characteristic & $\begin{array}{l}\text { Control } \\
(\mathrm{N}=105)\end{array}$ & $\begin{array}{l}\text { Internet } \\
(\mathrm{N}=104)\end{array}$ & $\begin{array}{l}\text { Face to Face } \\
(\mathrm{N}=105)\end{array}$ \\
\hline Female sex (\%) & 82.9 & 80.8 & 80.0 \\
\hline Age (yr) & $52.0 \pm 10.8$ & $50.9 \pm 9.3$ & $51.0 \pm 10.3$ \\
\hline Weight (kg) & $78.8 \pm 14.8$ & $76.0 \pm 16.4$ & $78.6 \pm 17.1$ \\
\hline Body-mass index' & $29.1 \pm 5.0$ & $28.1 \pm 4.6$ & $28.7 \pm 4.7$ \\
\hline Weight loss from highest weight in prior $2 \mathrm{yr}(\mathrm{kg})$ & $18.6 \pm 10.3$ & $19.2 \pm 11.1$ & $20.0 \pm 11.6$ \\
\hline Weight loss from highest weight in prior $2 \mathrm{yr}(\%)$ & $17.9 \pm 7.0$ & $18.3 \pm 7.7$ & $19.1 \pm 8.0$ \\
\hline Duration of weight loss (mo) & $13.1 \pm 8.1$ & $12.8 \pm 7.3$ & $13.7 \pm 7.0$ \\
\hline Caloric intake (kcal/day) & $1562 \pm 617$ & $1693 \pm 610$ & $1636 \pm 635$ \\
\hline Calories from fat $(\%) \ddagger$ & $33.5 \pm 8.8$ & $34.5 \pm 8.3$ & $35.0 \pm 8.8$ \\
\hline Physical activity (kcal/wk)』 & $1794 \pm 1295$ & $2194 \pm 1557$ & $1990 \pm 1460$ \\
\hline
\end{tabular}




\begin{tabular}{|c|c|c|c|}
\hline \multirow[t]{2}{*}{ Interval } & \multirow[t]{2}{*}{$\begin{array}{c}\text { Control } \\
(\mathrm{N}=105)\end{array}$} & $\begin{array}{l}\text { Internet } \\
(\mathrm{N}=104)\end{array}$ & \multirow[t]{2}{*}{$\begin{array}{l}\text { Face to Face } \\
(\mathrm{N}=105)\end{array}$} \\
\hline & & kilograms & \\
\hline Baseline to $6 \mathrm{mo}$ & $1.5 \pm 3.6$ & $1.2 \pm 4.2$ & $-0.02 \pm 4.3 \dagger$ \\
\hline Baseline to $12 \mathrm{mo}$ & $3.0 \pm 5.7$ & $3.1 \pm 7.5$ & $1.3 \pm 6.0$ \\
\hline Baseline to $18 \mathrm{mo}$ & $4.9 \pm 6.5$ & $4.7 \pm 8.6$ & $2.5 \pm 6.7 \div$ \\
\hline \multicolumn{4}{|c|}{ 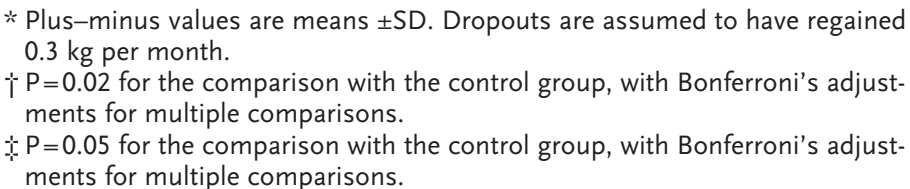 } \\
\hline
\end{tabular}

$18 \%$; $95 \%$ CI, 5 to $30 ; \mathrm{P}=0.008$ ) and $45.7 \%$ of participants in the face-to-face group (absolute difference, 27\%; 95\% CI, 14 to 39; P<0.001) (Fig. 3). There was no significant difference in the percentage who regained $2.3 \mathrm{~kg}$ or more between the two intervention groups (absolute difference, $9 \% ; 95 \% \mathrm{CI},-4$ to $23 ; \mathrm{P}=0.19$ ).

\section{EFFECT OF INTERVENTIONS ON THE PREVENTION OF WEIGHT REGAIN}

Of the 314 participants in the study, $34.7 \%$ remained consistently in the green or yellow zone at 6,12 , and 18 months, including $43.8 \%$ of those in the face-to-face group, $37.5 \%$ of those in the Internet group, and $22.9 \%$ of those in the control group. There was a significant difference in these percentages between the control group and the face-to-face group (absolute difference, 21\%; 95\% CI, 9 to 33; $\mathrm{P}=0.001$ ) and the control group and the Internet group (absolute difference, 15\%; 95\% CI, 2 to 27; $\mathrm{P}=0.02$ ), but not between the intervention groups (absolute difference, $6 \%$; $95 \% \mathrm{CI}$, -7 to $20 ; \mathrm{P}=0.35$ ). In contrast, only 23 of the 166 participants (13.9\%) who regained $2.3 \mathrm{~kg}$ or more at 6 or 12 months subsequently returned to the green or yellow zone, with no significant difference among the face-to-face, Internet, and control groups (19.2\%, $16.0 \%$, and $7.8 \%$, respectively). The difference between the face-to-face group and the control group approached significance $(\mathrm{P}=0.07)$, but the Internet group did not differ significantly from the face-to-face group $(\mathrm{P}=0.99)$ or the control group $(\mathrm{P}=0.17)$.

\section{ADHERENCE}

Attendance at the face-to-face and chat-room sessions decreased over time $(\mathrm{P}<0.001)$ but was

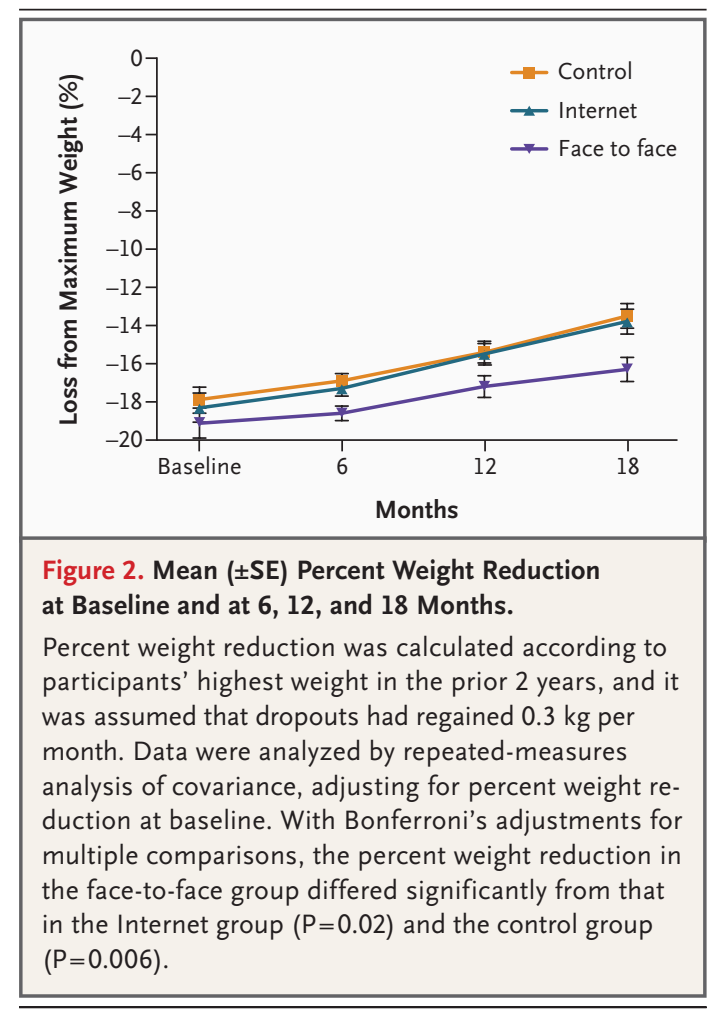

consistently better in the face-to-face group than in the Internet group $(\mathrm{P}=0.005)$. The percentage of sessions attended by participants in the face-to-face group was $78.7 \%$ from baseline to 6 months, $53.5 \%$ from 7 to 12 months, and $41.5 \%$ from 13 to 18 months, as compared with $65.7 \%$, $41.2 \%$, and $34.2 \%$, respectively, in the Internet group. The percentage of participants who reported their weight each week also decreased over time $(\mathrm{P}<0.001)$, but the difference between the two intervention groups was not significant. In the face-to-face group, the percentage of participants who reported their weight was $84.0 \%$ from baseline to 6 months, $68.6 \%$ from 7 to 12 months, and $56.1 \%$ from 13 to 18 months, and in the Internet group the respective percentages were $82.0 \%, 69.1 \%$, and $55.3 \%$.

\section{ADVERSE EVENTS}

Medical and psychological adverse events were monitored throughout the trial. No serious adverse events were related to the interventions (Fig. 1).

\section{BEHAVIORAL CHANGES}

Despite the differences in regained weight, there were no significant differences in changes in caloric intake, percentage of calories from fat, or 


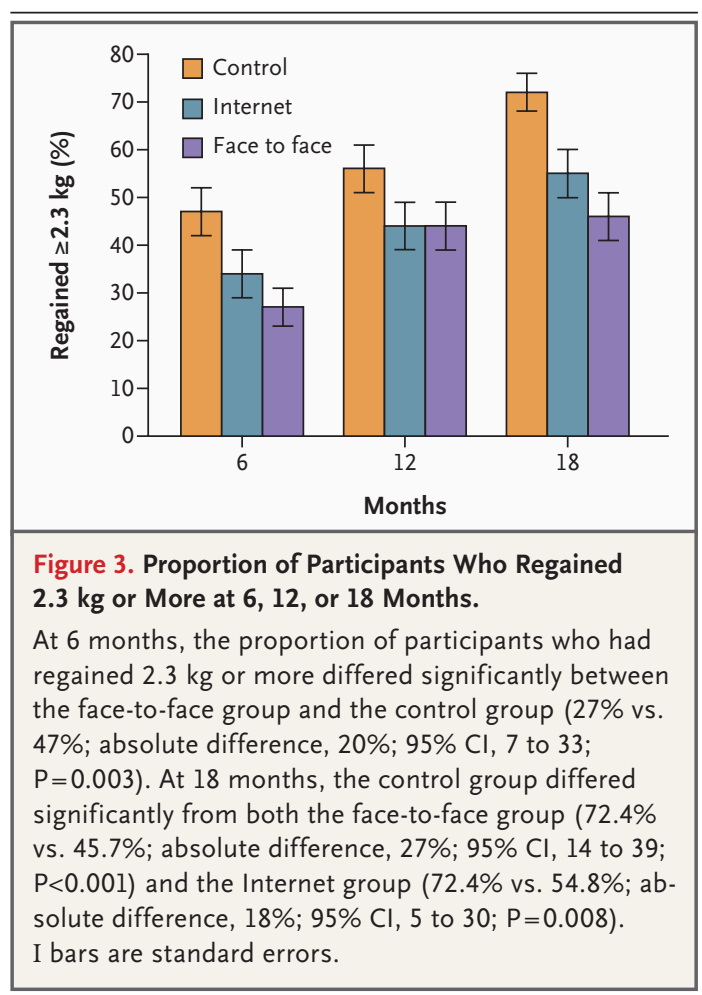

physical activity among the groups. However, there were significant differences in the participants' ratings of the importance of key behavioral strategies. Both intervention groups gave higher ratings for self-weighing as an important aspect of their weight-control efforts than did the control group $(\mathrm{P}=0.001)$. The face-to-face group, as compared with the control group, also gave higher ratings for setting a weight-loss goal $(\mathrm{P}=0.005)$, counting calories $(\mathrm{P}=0.03)$, and keeping a graph or record of eating and exercise $(\mathrm{P}=0.01)$.

Since self-weighing is a key component of the self-regulation model, we compared the proportion of participants in each group who reported weighing themselves at least daily. Differences between treatment groups were significant at 6,12 , and 18 months $(\mathrm{P}<0.001$ for all pairwise comparisons); during each period, 28.9 to $40.0 \%$ of participants in the control group reported daily weighing, as compared with 65.1 to $81.4 \%$ of participants in the Internet group and 71.2 to $78.9 \%$ of participants in the face-to-face group. In addition, in the face-to-face and Internet groups, a smaller proportion of participants who weighed themselves daily regained $2.3 \mathrm{~kg}$ or more, as compared with those who weighed themselves less often (face-to-face group, $26.2 \%$ vs. $58.3 \%$; abso-

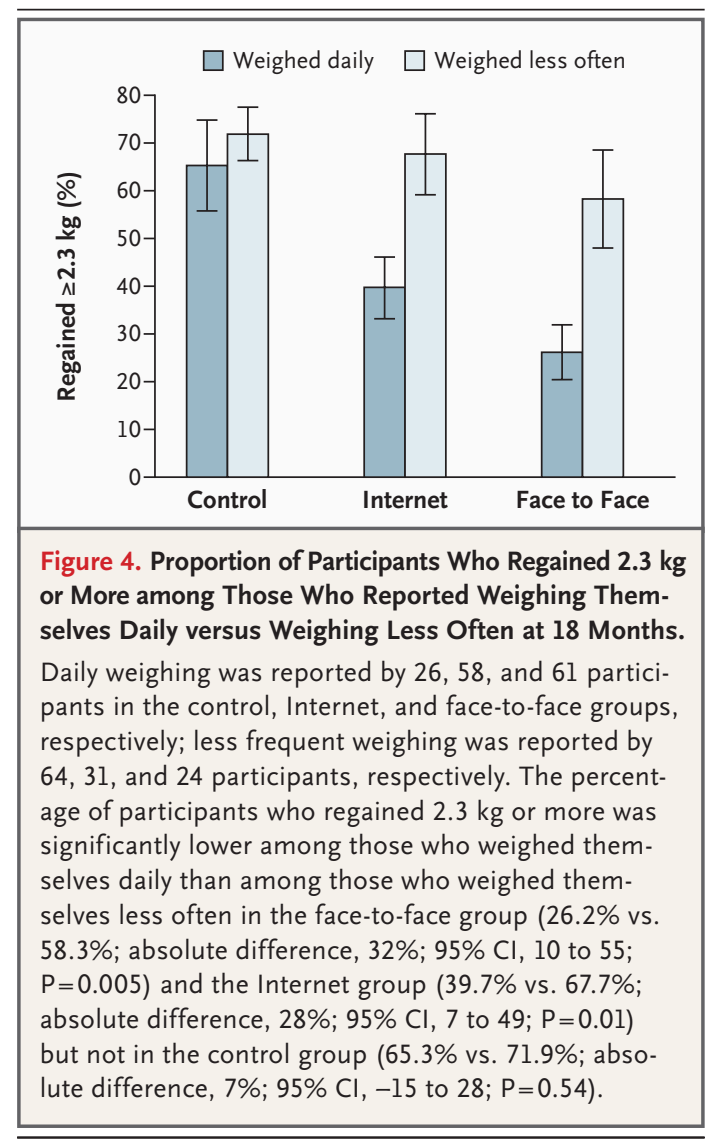

lute difference, 32\%; 95\% CI, 10 to 55; $\mathrm{P}=0.005$; Internet group, $39.7 \%$ vs. $67.7 \%$; absolute difference, $28 \%$; $95 \% \mathrm{CI}, 7$ to 49 ; $\mathrm{P}=0.01$ ). In the control group, the difference was much smaller (65.3\% vs. $71.9 \%$; absolute difference, $7 \%$; $95 \% \mathrm{CI}$, -15 to $28 ; \mathrm{P}=0.54$ ) (Fig. 4).

\section{DISCUSSION}

A major problem in the treatment of obesity is maintenance of weight loss. Our results suggest that with minimal intervention, $72 \%$ of successful dieters will regain more than $2.3 \mathrm{~kg}$ over a period of 18 months. The interventions used in our study, which focused on teaching self-regulation of body weight, significantly decreased the risk of regaining $2.3 \mathrm{~kg}$ or more. However, only the face-to-face format reduced the amount of weight regained.

We recruited participants who had recently lost a clinically important amount of weight, regardless of how they had lost the weight, and taught them strategies to prevent weight regain instead of promoting further weight loss. The efficacy of 
the interventions we tested suggests that this concept of a separate and distinct weight-loss maintenance program may be important for the successful treatment of obesity. In this study and a prior study, ${ }^{20}$ preventing weight regain appears to be critical because of the difficulty of reversing even small weight regains.

The face-to-face format produced the best outcomes in this trial, with an average weight gain of $2.5 \mathrm{~kg}$ and $46 \%$ of participants regaining $2.3 \mathrm{~kg}$ or more. Attendance was also superior in the faceto-face group. The Internet intervention was effective in decreasing the proportion of participants who regained weight, but it was less effective in reducing the amount of weight regained. Therefore, from a public health perspective, it might be desirable to use the Internet strategy for prevention of weight regain but to add face-to-face or telephone counseling if weight is regained.

The proportion of participants who reported daily self-weighing was significantly higher in the intervention groups than in the control group, and daily self-weighing was strongly associated with successful weight-loss maintenance. However, frequent self-weighing could be either a cause or a consequence of weight-loss maintenance. The fact that participants in the intervention groups had been taught to use their weight data to regulate their eating and exercise behaviors may be what made this strategy effective for these groups but not for the control group. Several recent studies have shown the importance of frequent selfweighing for both prevention of weight gain and weight loss ${ }^{21}$ and clinical guidelines of the $\mathrm{Na}$ tional Heart, Lung, and Blood Institute ${ }^{7}$ state that "regular self-monitoring of weight is critical for long-term maintenance." Although concern has been expressed about possible adverse effects of regular self-weighing, there is little evidence to support this concern ${ }^{22}$ and no evidence of adverse consequences of the interventions in our trial.

The strengths of our study include the selection of a cohort of successful dieters (who had an average weight loss of more than $19 \mathrm{~kg}$ at baseline), the randomized design, and the fact that 93\% of participants completed the 18-month followup. Limitations include failure to find differences in dietary intake or activity, perhaps reflecting the limitations of using self-reported measures, ${ }^{23}$ and the inability to determine whether self-regulation was more effective than other approaches to weight-loss maintenance and which aspects of the intervention were most important.

In conclusion, the two self-regulation interventions were more effective than the use of newsletters in maintaining weight loss for the duration of the study. The face-to-face intervention decreased the amount of weight regained, but both the Internet and the face-to-face interventions decreased the risk of regaining $2.3 \mathrm{~kg}$ or more. Future studies should examine ways to refine these interventions in order to improve their efficacy.

Supported by a grant (DK57413) from the National Institute of Diabetes and Digestive and Kidney Diseases.

Dr. Wing reports having received consulting fees from Sanofi and Pfizer; and Dr. Tate, lecture fees from Unilever. No other potential conflict of interest relevant to this article was reported.

We are indebted to Natalie Robinson, Elizabeth Jackvony, Deborah Sepinwall, Jacki Hecht, and Marta Roberts for their contributions in coordinating the study and providing the interventions; to Jason Peng and Jason Machan for data management and statistical support; to Kristen Whitehead for administrative support; and to all the STOP Regain participants.

\section{REFERENCES}

1. Wing RR. Behavioral approaches to the treatment of obesity. In: Bray GA, Bouchard C, eds. Handbook of obesity: clinical applications. New York: Marcel Dekker 2004:147-67.

2. Knowler WC, Barrett-Connor E, Fowler SE, et al. Reduction in the incidence of type 2 diabetes with lifestyle intervention or metformin. N Engl J Med 2002;346:393403.

3. Wadden TA, Phelan S. Behavioral assessment of the obese patient. In: Wadden TA, Stunkard AJ, eds. Handbook of obesity treatment. New York: Guilford Press 2002:186-226.

4. Perri MG, Corsica JA. Improving the maintenance of weight lost in behaviora treatment of obesity. In: Wadden TA Stunkard AJ, eds. Handbook of obesity treatment. New York: Guilford Press, 2002: 357-79.

5. Kanfer FH, Goldstein AP, eds. Helping people change: a textbook of methods New York: Pergamon Press, 1975.

6. Wing RR, Epstein LH, Nowalk MP Lamparski DM. Behavioral self-regulation in the treatment of patients with diabetes mellitus. Psychol Bull 1986;99:78-89.

7. National Institutes of Health. Clinical guidelines on the identification, evaluation, and treatment of overweight and obesity in adults - The Evidence Report. Obes Res 1998;6:Suppl 2:51S-209S. [Erratum, Obes Res 1998;6:464.]

8. McGuire MT, Wing RR, Klem ML, Lang W, Hill JO. What predicts weight regain in a group of successful weight losers? J Consult Clin Psychol 1999;67:177-
85. [Erratum, J Consult Clin Psychol 1999; 67:282.]

9. Tate DF, Jackvony EH, Wing RR. Effects of Internet behavioral counseling on weight loss in adults at risk for type 2 diabetes: a randomized trial. JAMA 2003;289:1833-6. 10. Tate DF, Wing RR, Winett RA. Using Internet technology to deliver a behavioral weight loss program. JAMA 2001;285: 1172-7.

11. Harvey-Berino J, Pintauro S, Buzzell P, Gold EC. Effect of Internet support on the long-term maintenance of weight loss. Obes Res 2004;12:320-9.

12. Baker RC, Kirschenbaum DS. Weight control during the holidays: highly consistent self-monitoring as a potentially useful coping mechanism. Health Psychol 1998;17:367-70. 
13. Klem ML, Wing RR, McGuire MT, Seagle HM, Hill JO. A descriptive study of individuals successful at long-term maintenance of substantial weight loss. Am J Clin Nutr 1997;66:239-46.

14. Wing RR, Hill JO. Successful weight loss maintenance. Annu Rev Nutr 2001;21 323-41.

15. Stevens J, Truesdale KP, McClain JE, Cai J. The definition of weight mainte nance. Int J Obes (Lond) 2006;30:391-9.

16. Paffenbarger RS Jr, Wing AL, Hyde RT.

Physical activity as an index of heart at-

tack risk in college alumni. Am J Epidemiol

1978;108:161-75.

17. Block G, Hartman AM, Dresser CM
Carroll MD, Gannon J, Gardner L. A databased approach to diet questionnaire design and testing. Am J Epidemiol 1986 124:453-69.

18. Wadden TA, Berkowitz RI, Womble LG et al. Randomized trial of lifestyle modification and pharmacotherapy for obesity. N Engl J Med 2005;353:2111-20.

19. Wadden TA, Berkowitz RA, Sarwer DB, Prus-Wisniewski R, Steinberg C. Benefits of lifestyle modification in the pharmacologic treatment of obesity: a random ized trial. Arch Intern Med 2001;161:218 27.

20. Phelan S, Hill JO, Lang W, Dibello JR, Wing RR. Recovery from relapse among successful weight maintainers. Am J Clin Nutr 2003;78:1079-84.

21. Linde JA, Jeffery RW, French SA, Pronk NP, Boyle RG. Self-weighing in weight gain prevention and weight loss trials. Ann Behav Med 2005;30:210-6.

22. O'Neil PM, Brown JD. Weighing the evidence: benefits of regular weight monitoring for weight control. J Nutr Educ Behav 2005;37:319-22.

23. Lichtman SW, Pisarska K, Berman ER, et al. Discrepancy between self-reported and actual caloric intake and exercise in obese participants. N Engl J Med 1992;327:

1893-8.

Copyright (c) 2006 Massachusetts Medical Society. 